\section{$\underset{\substack{\text { hommes } \\ \text { \& migrations }}}{ }$}

\section{Hommes \& migrations}

Revue française de référence sur les dynamiques

migratoires

$1326 \mid 2019$

Londres et ses migrations

\title{
Le Brexit et l'immigration européenne à Londres
}

\section{Catherine Wihtol de Wenden}

Traducteur : Vanessa Kientz

\section{CpenEdition}

Journals

Édition électronique

URL : https://journals.openedition.org/hommesmigrations/9602

DOI : 10.4000/hommesmigrations.9602

ISSN : 2262-3353

Éditeur

Musée national de l'histoire de l'immigration

Édition imprimée

Date de publication : 1 juillet 2019

Pagination : $37-41$

ISBN : 978-2-919040-46-9

ISSN : 1142-852X

Référence électronique

Catherine Wihtol de Wenden, « Le Brexit et l'immigration européenne à Londres », Hommes \&

migrations [En ligne], 1326 | 2019, mis en ligne le 01 janvier 2022, consulté le 14 janvier 2022. URL:

http://journals.openedition.org/hommesmigrations/9602 ; DOI : https://doi.org/10.4000/

hommesmigrations.9602 


\section{Le Brexit \\ et l'immigration \\ européenne à Londres}

Catherine Wihtol de Wenden,

politologue, directrice de recherche au CNRS (Ceri).

Le Brexit va considérablement modifier les relations migratoires entre le Royaume-Uni et l'Union européenne. Formalités administratives, équivalence des diplômes, droit d'asile... sont autant d'aspects concernés par ce changement politique qui va toucher tout autant les Européens résidant en Grande-Bretagne que les Britanniques installés en Europe. Si l'attrait pour le Royaume-Uni comme terre d'immigration de courte durée risque de diminuer, les pays européens devront, quant à eux, inventer de nouveaux statuts pour les Britanniques installés sur leur sol.

I

I est toujours difficile de se lancer dans une prospective à court terme sur l'immigration européenne à Londres, concernant un accord de sortie de l'Union européenne du RoyaumeUni, qui a obtenu un nouveau report flexible pour le 31 octobre 2019, date clé avant l'installation d'une nouvelle Commission européenne. Mais Londres est une ville qui, depuis longtemps, abrite de très nombreux Européens, réfugiés hier (protestants, proscrits politiques)' et, aujourd'hui, des étudiants et de jeunes professionnels souhaitant booster leur carrière. Les conséquences du Brexit sont multiples, tant pour les citoyens britanniques résidant dans les 27 États de l'Union européenne que pour les Européens résidant au Royaume-Uni.

Avant de considérer la situation des Européens au Royaume-Uni et notamment à Londres, on se penchera brièvement sur le sort des Britanniques dans l'UE, car leurs conditions ont partie liée.

\section{Quels droits pour les Britanniques dans l'Union européenne?}

Pour les citoyens britanniques résidant dans l'Union européenne, les droits attachés à la citoyenneté européenne (notamment la liberté de circuler, de s'installer et de travailler en Europe, ainsi que le droit de vote et l'éligibilité aux élections locales) devraient s'éteindre, sous réserve de la décision souveraine de chaque pays de l'Union et d'accords bilatéraux avec le Royaume-Uni. Certains Britanniques ont ainsi candidaté pour l'accès à la nationalité de leur pays d'installation: en Belgique pour les anciens fonctionnaires européens, en France pour les résidents,

1. Debra Kelly, Martyn Cornick (dir.), A history of the French in London. Liberty, equality, opportunity, Londres, Institute of Historical research, 2013. Voir l'encadré ci-dessous. 
parfois «seniors au soleil», ayant créé une sorte de «Britishland» dans le Sud et l'Ouest du pays. À l'exception de l'Irlande, où les Britanniques, comme tous les étrangers, ont accès au droit de vote à toutes les élections sans condition de durée de séjour, tous les autres pays européens devront statuer sur les Britanniques, en modifiant leur constitution ou leur législation électorale selon les cas. On peut imaginer que, pour beaucoup de Britanniques, la double nationalité va se développer.

Selon La Lettre de la Citoyennetée, trois cas de figure sont envisageables pour l'exercice de la citoyenneté européenne pour les Britanniques à l'échelon local: s'ils résident dans des pays européens ayant accordé le droit de vote et à l'échelle locale à tous les étrangers (une quinzaine), ils resteront électeurs et éligibles. S'ils résident dans des pays où les droits aux étrangers sont accordés en fonction d'accords de réciprocité (Espagne et Portugal), ces États d'accueil pourront signer des accords avec le Royaume-Uni. Les Britanniques retraités sont nombreux dans le Sud de l'Espagne et du Portugal, et on peut présumer qu'ils pèseront pour influer au niveau local sur ces accords potentiels. Dans les autres pays européens, ils ne seront plus électeurs ni éligibles à l'échelon local, comme en France où certains villages de l'ouest et du sud du pays ont une majorité de ressortissants britanniques. Les droits qu'ils ont exercés pourraient faire l'objet d'un accord entre le Royaume-Uni et l'Union européenne. Selon la lettre de la citoyenneté: «Le retrait du droit de vote et d'éligibilité aux Britanniques vivant sur le territoire serait un recul de la démocratie représentative. II pourrait être interprété comme un geste de représailles pénalisant des Britanniques vivant sur le territoire alors qu'ils ont montré leur volonté d'intégration à la vie sociale et politique du pays. » On dénombre environ 400 conseillers municipaux britanniques en France, selon Michel Barnier.

\section{De nouvelles frontières extérieures}

Une autre question concerne la frontière entre l'Irlande du Nord et l'Irlande du Sud, puisque l'Irlande du Sud, indépendante, reste dans l'Union européenne et que sa frontière avec l'Irlande du Nord, britannique, va devenir une frontière externe de l'Union européenne, soumise aux accords de Schengen de renforcement des frontières extérieures de l'Union, avec des points de passage potentiels, des contrôles frontaliers et d'éventuels trafics.
La question de Calais est moins sujette à changements, puisque c'est parce que le Royaume-Uni n'a jamais fait partie des Accords de Schengen que les non-Européens ayant traversé l'Europe depuis l'Afghanistan, la Syrie, l'Irak ou venant de pays africains se sont fracassés sur les contrôles policiers britanniques à l'extrême limite géographique de la France, et non parce que le Royaume-Uni était dans l'Union européenne mais contrôlait ses frontières sur le sol français. En revanche, les Accords de Dublin sur l'asile ne s'appliqueront plus au Royaume-Uni qui continuera à appliquer la Convention de Genève mais ne sera plus lié par le projet d'harmonisation européenne de l'asile.

\section{Les Européens du Royaume-Uni et notamment de Londres}

Quelque 3 millions de citoyens européens vivent au Royaume-Uni. Les universités accueillent de nombreux étudiants européens, les bureaux d'avocats sont souvent pluri-nationaux, tout comme les banques et les start-up qui forment les futurs businessmen. Le secteur de la restauration, du tourisme ainsi que de la construction emploient de nombreux Polonais qui ont été accusés de concurrencer les Britanniques et les ressortissants du Commonwealth dans ces métiers moins qualifiés. Le rapport du Système d'observation permanente des migrations (Sopemi) en 2018 enregistrait, au Royaume-Uni, 149000 acquisitions de nationalité britannique en 2016, faisant du Royaume-Uni le second pays après l'Italie (201000 en 2016) pour l'acquisition de la nationalité, devant la France (119000 en 2016) et l'Allemagne (110 000). Il est à penser que l'attrait pour la citoyenneté britannique sera moindre pour les Européens et que nombre d'entre eux, les professionnels surtout, quitteront le Royaume-Uni.

En 2017, le pays comptait, selon le Sopemi, 6 millions d'étrangers, dont 994000 Polonais, 382000 Roumains, 343000 Irlandais, 296000 Italiens, 269000 Portugais, 196000 Lituaniens, 191000 Espagnols, 186000 Français, 131000 Allemands, 119000 Lettons, 109000 Bulgares. Les pays d'Europe centrale et orientale sont présents dans l'ensemble du pays pour travailler dans des métiers moins qualifiés comme l'agriculture et le bâtiment, tandis que les

2. La Lettre de la Citoyenneté, $n^{\circ} 150$, «Les conséquences du Brexit », novembre-décembre 2017. 


\section{Debra Kelly, Martyn Cornick (dir.), A History of the French in London. Liberty, Equality, Opportunity, Londres, Institute of Historical Research, 2013, 488 p.}

Cet ouvrage rend compte de trois siècles de recherches sur les Français à Londres, ville des immigrants mais aussi « City of nations», marquée par l'histoire politique qui sous-tend cette succession de profils. Il se demande si les Français à Londres se considèrent comme une communauté et quel héritage ils se sont transmis. Réfugiés politiques de droite et de gauche au long des XVIIe, $X V I I I{ }^{e}$ et XIXe siècles, artistes, exilés, résistants, intellectuels, jeunes diplômés ont considéré Londres comme "the Global City», offrant, comme l'indique le sous-titre du livre, liberté, égalité et opportunités pour un cosmopolitisme à usage personnel ("self cosmopolitisation»). Certains la considèrent comme le $21^{1}$ arrondissement de Paris, formant un entre soi, une communauté qui pourtant critique le communautarisme.

L'ouvrage commence à la veille de 1685 , quand les protestants chassés de France par Louis XIV avec la révocation de l'Édit de Nantes viennent apporter à Londres leur savoir-faire (comme orfèvres, tisserands) et leurs connaissances (imprimeurs) (Elisabeth Randall). Le goût français existe déjà, par la présence de la haute société et notamment des ambassadeurs de France (Paul Boucher et Tessa Murdoch). Avec la Révolution française, aristocrates et membres du clergé y perpétuent ce goût français avant de retourner en France après 1814 (Kirsty Carpenter). En 1830, ce sont les royalistes qui sont à nouveau en exil, un exil facilité par les transports (Londres n'est qu'à 30 heures de Paris avec les bateaux à vapeur). Londres devient la capitale de la vie française en exil, où royalistes et bonapartistes $\mathrm{y}$ font leur propagande politique à distance, ce moment anglo-français apparaissant, pour la France, comme un facteur de modernisation (l'attachement à l'urbanisme et aux espaces verts de Napoléon III serait né, dit-on, de sa vie à Londres, qu'il essaiera de transposer à Paris avec Haussmann) (Philip Montel). Au milieu du XIX siècle, Maire Cross montre combien l'occupation des visiteurs français à Londres devient multidimensionnelle, avec des exilés de tous bords, de l'extrême gauche à l'extrême droite, sans oublier des femmes comme Flora Tristan, des personnages comme Tocqueville ou Michelet. Républicains et communistes en exil sont là également, adeptes de Marx et Engels ou blanquistes (1848 et après le coup d'État du 2 décembre 1851 de Louis-Napoléon Bonaparte) (Fabrice Bensimon). Après l'amnistie de 1859 à leur égard, ce sont les communards qui leur succèdent entre 1871 et 1880 (nouvelle amnistie). C'est en partie grâce à eux que se fera l'introduction des idées marxistes en France (Thomas Jones et Robert Tombs). Des anarchistes français fréquentent également Londres entre 1870 et 1914 (Constance Bantman). Tous ces Français, aussi disparates soient-ils, y importent la cuisine française, raffinée ou bourgeoise, et fréquentent leurs restaurants (Valérie Mars à propos du guide touristique Bedecker). Michel Rapoport dresse des portraits des Français célèbres de la fin du $X I X$ siècle à l'entre-deux-guerres, le général Boulanger, Henri de Rochefort, Émile Zola (après l'éclatement de l'Affaire Dreyfus et avant la réhabilitation de ce dernier). Beaucoup participent au "soft power», sont des acteurs aux sentiments anglophiles de l'entente cordiale franco-anglaise (1904), car Londres est un "safe heaven», la capitale des libertés (Philippe Lane et Charlotte Faucher). Autre moment majeur, l'Occupation voit $y$ arriver les réfugiés et exilés du nazisme, les gaullistes, une population jeune et urbaine venue avant et après l'appel du 18 juin 1940, liée à la BBC (Debra Kelly). On y rencontre Raymond Aron, journaliste à La France libre (David Drake). Enfin, la population française à Londres aujourd'hui (Helen Drake et Sakia Huc), tout aussi diversifiée, se différencie des vagues précédentes des réfugiés et des politiques, car ce sont des professionnels souvent qualifiés (Londres attire $35 \%$ des investisseurs français à l'étranger) qui reconstituent parfois un "ghetto français» comme à South Kensington. Le tunnel sous la Manche a continué à favoriser l'attraction de Londres pour les Français.

Cet excellent ouvrage nous plonge dans les différents milieux politiques, culturels et économiques des Français à Londres, leurs modes de vie, leurs idées politiques, leurs activités et leurs points communs malgré leur diversité. 
nationalités d'Europe de l'Ouest sont en majorité présentes dans les grandes villes et surtout à Londres. On compte une moyenne de $52 \%$ de femmes, plus nombreuse chez les Allemands (62\%) et les Irlandais (56\%). Selon le barreau de Paris, des cabinets d'avocats installés à Londres ont commencé à rapatrier leurs nationaux français, tandis que l'interrogation plane sur la composition future des lobbies auprès des institutions européennes, où les Britanniques étaient bien implantés, accoutumés à la technique du groupe de pression et travaillant dans leur langue. Des ex-fonctionnaires européens de Bruxelles ont même entamé une procédure d'acquisition de la nationalité belge pour continuer à vivre dans la capitale belge.

À Londres, les bénéficiaires du départ des Européens seront les nationalités du Commonwealth, Indiens et Pakistanais, largement favorables au Brexit à cause de la concurrence qu'ils faisaient assumer aux Européens (et notamment aux Polonais) dans leurs métiers (restauration, entretien). Ils représentent une puissante force électorale car ils votent à toutes les élections au Royaume-Uni et pèsent donc d'un poids politique non négligeable. Ils sont présents à la Chambre des Communes, mais aussi à la Chambre des Lords, où ils peuvent être nommés en gratification, et surtout au niveau local.

L'interrogation essentielle porte sur les étudiants européens accueillis à Londres. Selon la Commission européenne ${ }^{3}$, le Royaume-Uni fait partie du top 5 pour les étudiants Erasmus accueillis. Pour l'année 2013-2014, la primeur va à l'Espagne (39277), puis l'Allemagne (30964), la France (29621), le Royaume-Uni (27401) et l'Italie (20204). Pour les étudiants partis à l'étranger, les Britanniques sont beaucoup moins nombreux (15610) que leurs homologues européens du top 5: Espagne (37235), France (36759), Allemagne (36257), Italie (26331).

3. Source : Commission européenne, Le Monde, 6 janvier 2017. 
Quid également des modalités de circulation pour ces étudiants au sein de l'Union européenne? Des visas? Un régime de libre circulation aménagé? Et pour les étudiants de plus longue durée, les stagiaires et autres professionnels circulant entre l'Europe et le Royaume-Unis? Quid du commerce avec le Royaume-Uni et de l'activité trans-Manche qui fait vivre en partie la région de Calais?

\section{Conclusion}

On constate, depuis 2016, une baisse du solde migratoire ${ }^{4}$ des ressortissants venant de l'Union européenne au Royaume-Uni, bien que les entrées demeurent supérieures aux départs (+ 90000 personnes). Mais l'attrait pour le Royaume-Uni comme terre d'immigration de courte durée sera moindre car les formalités administratives seront amenées à se complexifier, le passage de la frontière plus bureaucratique, l'équivalence des diplômes vraisemblablement réexaminée et l'acquis professionnel réévalué au bénéfice d'autres pays européens (Allemagne notamment).

4. On définit par solde migratoire la différence entre le nombre d'entrants et celui des sortants. 